Copyright (C) 2021 The Author/s

This work is licensed under a CC-BY 3.0 License

Peer review method: Double-Blind

Accepted: September 09, 2021

Published: September 21, 2021

Original scientific article

DOI: https://doi.org/10.47305/JLIA2137085d

\title{
CHALLENGES AND DIFFICULTIES FOR MICRO-BUSINESSES IN ADAPTING IFRS FOR SMES REQUIREMENTS: KOSOVO EVIDENCE
}

\author{
Esat A. Durguti* \\ University "Isa Boletini", Faculty of Economy - Mitrovica, Kosovo \\ ORCID iD: https://orcid.org/0000-0002-5982-3664 \\ esat.durguti@umib.net \\ Erëza A. Arifi \\ College for International Management - Prishtina, Kosovo \\ ORCID iD: https://orcid.org/0000-0001-5197-1606 \\ ereza.arifi@kolegjiglobus.com
}

\begin{abstract}
Small and medium-sized enterprises (SMES) have a vital position in the international economy. The study aims to examine the compulsory financial reporting requirements set by the Kosovo Council for Financial Reporting (KCFR) as well as SMEs requirements for reviewing the current classification in the Kosovo context. This study, like most relevant studies, employs ordinal probit regression to examine the relationships among the requirements defined as dependent variables and other control variables such as necessary reclassification review under KCFR, preferred reclassification review under KCFR, experience knowledge of accountants and auditors, continuously education concerning financial reporting, and assessments of business owners. According to the reported conclusions, the application of these requirements in the Kosovo context does not create any opportunities for SMEs. On the contrary, the findings point to a thorough review of the reporting requirements for microbusinesses, as the current classification appears to be a burden for these businesses.
\end{abstract}

Keywords: Small and Medium-Sized Enterprises; Kosovo; International Financial Reporting Standards

\section{INTRODUCTION}

Globalization, particularly commercial globalization, is an undeniable reality nowadays, and so evidence on the cultural, socioeconomic, and human resource circumstances of business organizations is extremely valuable. Because Small and Medium-Sized Enterprises (SMEs) have played a significant role in the process of globalization and the strengthening of the global economy, the accounting evidence presented by SMEs is essential. Evidence about SMEs, such as who uses accounting 
evidence, comparability, and harmonization of this evidence, could be improved further to reduce the asymmetry of information. In this perspective, policymakers' roles as drafters of accounting standards should be recognized as a vital step in this regard. The IFRS for SMEs was officially published in July 2009. The IFRS for SMEs signifies a very important step towards the worldwide convergence of SME financial statements performs. These standards will assist to enhance the quality and comparison of SMEs' financial reports throughout the world, as well as provide SMEs with another avenue for accessing and financing around the world (Neag, Masca, and Pascan 2009).

Initially, the accounting system and its application in Kosovo were created on Regulation No. 2001/30 'On the establishment of the board of the financial statements of Kosovo and the financial reporting command of the business organizations'. With the implementation of Law No. 06/L-032 on Accounting, Financial Reporting, and Audit, articles 5 and 11 involve large businesses to formulate financial statements under IFRS.

By KCRF's recommendation and the Ministry of Finance's endorsement on 1 January 2020, SMEs are required to implement ISA and IFRS for SMEs based on the stated categorization. However, according to relevant data, the great majority of businesses in Kosovo are classified as micro-enterprises; despite the categorization of this category into subcategories, businesses continue to perceive these criteria as obstacles to their development.

According to Law 06/L-032, is extracted Administrative order No. 01/2020 on micro-enterprises annual financial reporting defined in article 4, which specifies clearly that micro-enterprises are enterprises who do not extend to at tiniest two of the next three conditions: 1) statement of financial position (with total assets) 350,000 EUR, 2) annual revenue up to 700,000 EUR, and 3) an average number of employees up to 10 . Furthermore, the subclassification of micro-enterprises in 3 (three) classes was made as a result of this classification, under article 5 of this administrative Order. Based on the sample we have selected, this study assesses the viewpoint of all three groups: company owners, certified accountants, and legal auditors, as a result of IFRS requirements, they are recognized as a barrier to the growth of the business for the first two categories of article 5 since these two categories, up to EUR 300,000 per annum, are obligated to apply the IFRS of SMEs and to produce financial declarations.

Therefore, the research aims to determine the aspect of the obligations set out in current IFRS for SMEs, the difficulties and challenges experienced in particular by micro enterprises, based on the issues highlighted. To reach a more accurate argumentation, the study has posed some research questions as follows: 1) is the implementation of IFRS for SMEs a burden for micro-businesses given the fact that the vast majority of businesses are classified as micro-businesses, and 2) what is the perception of business owners, certified accountants on the application of these standards to these microbusinesses. The article context is designed to contribute to some important topics, first of all with a view to the extension of literature, particularly in Kosovo. Second, this 
research presents a quantitative analysis to avoid the contradictory dilemmas between the KCRF's and SME's requirements and micro-enterprises in particular. Third, the original empirical contribution is that the data were used by SMEs in Kosovo to investigate the requirements set by the KCRF and their effect in business evaluation using ordered probit regression. Finally, concerning the policy implications, it makes some major recommendations to examine the standards, particularly with regards to micro-enterprises, and to reform policies in this important sector.

\section{LITERATURE REVIEW AND HYPOTHESIS}

The financial crisis of 2007-2009 led a large number of studies to estimate the consequence of financial data value conferring to new standards with the ongoing adoption of the IFRSs towards the converging financial reporting in different states. The vast majority of research refers to forced adaptation (see Roca 2021; Sinem et al. 2021; Cormier et al. 2009), but there is also research on voluntary adaptation (Kouki 2018). Furthermore, certain researchers are also focused in other directions on effects on liquidity (Daske et al. 2008), capital cost handling (Daske 2006), evidence comparability (Callao et al. 2007), unintentional consequences (Brüggemann et al. 2013), and on the value of their application (Cormier and Magnan 2016; Závodný 2021).

Given the evolution, the research aims to examine the adverse consequences which have a specific focus on micro-businesses when adapting the standards under the present context. It should be mentioned that there is relatively little empirical research that discourse the aspect of burden and difficulties for the application of ISA and IFRS and this is a further incentive and contribution to this research. Among the few researchers that performed empirical investigation using terminology for economic consequences reflecting the influence on the value of the business financial report and the wealth of accounting-based policymakers are Zeff (1978), Leftwich (2016), and Brüggemann et al. (2013).

In their research 'The Intended and Unintended Effects of Mandatory IFRS Adoption' (Brüggemann et al. 2013) they tried therefore to identify the economic implications which they believe to be undesirable whether they are or do not correspond to the targets set out in the ISA and IFRS framework. There are different perspectives on the consequences of the mandatory implementation of IFRS around the world. But, in a large number of the literature, the results have not been uniform. IFRS benefits, on the other hand, only materialize in specific circumstances. Therefore investigations might be discovered with mixed findings. The study's results may be divided into three categories in terms of significance. The first group comprises research that establishes favorable relationships with value significance and IFRS implementation (Cormier and Magnan 2016; García et al. 2016). The second category comprises research 
in which the value of IFRS adoption is not augmented as improvements (Clarkson et al. 2011), or in which the relevance of the accounting number is reduced.

The third group contains research that reveals that the value of certain factors has improved, while the relevance of other variables has deteriorated (Chalmers et al. 2011). Despite the advantages described above, the IFRS continues to be of deep concern to SMEs, considering the possibility of exceeding the expected benefits at cost of adoption. Consequently, mixed reactions have continued to be expressed through debates on the elimination or softening of local reporting standards with IFRSs (Emmanuel et al. 2016). Furthermore, the authors Poroy and Sipahi (2007) note that the transition to IFRSs for SMEs will be difficult due to the low level of SMEs and the modifications between tax legislation and IFRSs for SMEs.

Regarding the advantages of admission to monetary markets (Riva and Salotti, 2015), SMEs tend to utilize internal resources rather than collect financing from banks. In addition, their analysis denies the statistical importance of accounting-related revelation linkages to the cost of borrowing. The query of whether the proposed IFRSs for SMEs will be appropriate for smaller units within the field of SMEs was raised by (Roberts and Sian 2006) in their research entitled 'Micro-Entity Financial Reporting: Perspectives of Preparers and Users'. Roberts and Sian (2006) caution that insufficient literacy, inadequate accounting training, and a lack of computerized accounting systems might undermine the capacity of these businesses in less developed economies to provide financial information under IFRSs.

Therefore, in the context of our study approach as well as the highlighted argument, we have put forward the main hypotheses on the necessity of reviewing the possibility of a conceivable re-classification in particular for micro-businesses. The hypotheses are as follows:

Ho: The need for the re-classification of KCRF necessities has a significant influence on the compulsory IFRS adaption and application requirements for SMEs.

Ha: The preferred re-classification of KCRF necessities has a significant influence on the compulsory IFRS adaption and application requirements for SMEs.

Since the numerous IFRS requirements for SME do not even apply to microentities, IASB has established, with the support of the team (SMEIG), a guide which sets out IFRS for SME, deprived of modifying any of the values for acknowledgment and quantity of assets and liabilities, earnings and expenses, and which are expected to be required for a typically microsize unit. Some changes to the expression are necessary to improve the design flow or for other reasons. Thus a possible modification or adaptation helps these units more easily identify the IFRS necessities for SMEs that are relevant to them. Several studies have focused particularly on the transitional stage of 
adopting those established standards, which is linked to the shortage of IFRS knowledge, difficulties adapting policies to each country, the degree of sufficient education, training, and other areas. Therefore, the study conducted by Lantto (2014) based on the methodology used by Byrne and Pierce (2007) has found that an increase in requirements by the regulator may affect a reduction in the ability of accountants to get involved in the business. Furthermore, the study elaborates on how knowledge is created through continuing learning required by IFRS approval, which is possible through specialized associations to obtain adequate knowledge. Furthermore, the authors Uyar and Güngörmüş (2013) analyzing the adaptation of IFRS for SMEs in the context of Turkey, have developed a questionnaire based on the requirements of IFRS for SMEs to investigate the knowledge and perceptions of accountants. Their findings argue that most respondents are not properly informed about IFRS for SME issues.

The study also argues that the commitment and training of adequate personnel, and the lack of training programs by specialized structures, are considered one of the weaknesses for the implementation of these standards. Finally, the assessment of the perception by business owners regarding these requirements are considered a burden for business development, which is indirectly underlined by Uyar and Güngörmüş (2013), that business owners must recruit adequate staff and invest in ongoing training for IFRS.

\section{RESEARCH APPROACH}

The study's goal is to empirically evaluate the preparation of financial statements defined by KCFR for small and medium-sized businesses. To accomplish this goal, the study is designed from both a theoretical and empirical standpoint.

The empirical aspect is based on the primary data provided by the questionnaires, with the main goal of providing the most reliable information on the mandatory requirements of the KCFR on the one hand, and the possibility of reviewing a possible reclassification that will not be considered an additional barrier for SMEs. Data were collected between August and September 2020, when 229 questionnaires were distributed to SMEs in a random sample, and all responses were received. The respondents were asked to respond to the prepared questions using the five 'Likert Scale' points, beginning with 1 (strongly disagree), 2 (disagree), 3 (neutral), 4 (agree), and 5 (strongly agree). The responses received from each respondent were then checked for logic flow to adjust the request for further treatment in empirical terms. To achieve the most consistent results, we first performed the statistical summary, followed by correlation analysis, other necessary tests, and finally the ordinary probit regression to ensure that the empirical approach was appropriately chosen. The ordinary probit regression (OPR) empirical approach was used in the study to determine the level of importance of the parameters used in the analysis. 


\section{ECONOMETRIC ANALYSIS}

Data and Sample

Data for 229 businesses were extracted from the official data of the Kosovo Business Registration Agency (KBRA) ${ }^{1}$ in June 2020 to assess the impact of mandatory KCFR requirements. These data were then cross-checked against the list of Tax Administration of Kosovo (TAK) are they active businesses. To obtain a representative sample for Kosovo, the survey used random sampling classified with scaled groups. The research design and data fall under the subdivisions regulated by the current legal framework. In this survey, businesses are classified as micro-businesses, small and medium-sized businesses, and large businesses, using the 3 (three) criteria outlined in the law for accounting, financial reporting, and auditing. The research is designed in such a manner that the actual assessment of the implementation of these requirements, and even the possibility of reclassification of these requirements, can be made. Respondents were questioned about their knowledge of the financial reporting aspect, the degree of difficulty of their application, the competence of their staff, and the need for the KCFR to reclassify these mandatory requirements. Table 1 displays the research's stratified random description, including business classification, number, and percentage participation.

Table 1: A summary of sample stratification (Source: KBRA and TAK, 2020. Authors' Calculation)

\begin{tabular}{|l|c|c|}
\hline \multicolumn{1}{|c|}{ Classification according to KCRF } & Number & $\%$ \\
\hline Micro-businesses with a turnover of up to 50,000 EUR & 87 & 37.9 \\
\hline Micro-businesses with a turnover of up to 300,000 EUR & 59 & 25.8 \\
\hline Micro-businesses with a turnover of over300,000 EUR & 43 & 18.8 \\
\hline Small and medium enterprises with a turnover of 300,000 - 700,000 EUR & 29 & 12.2 \\
\hline Small and medium enterprises with a turnover of over 700,000 EUR & 12 & 5.2 \\
\hline Total & 229 & 100.0 \\
\hline
\end{tabular}

Note: The sample was stratified according to the two in charge agencies, while business sorting is based on Law No. 06 / L-032.

Table 1 shows how the champion was stratified based on the degree of turnover of SMEs, revealing that 82.5 percent of the sample is concentrated in micro-businesses where the study is focused, with the remaining 17.5 percent being SMEs.

\footnotetext{
${ }^{1}$ See the Kosovo Business Registration Agency report entitled 'Basic Performance Indicators Report on Business Registration in Kosovo June 2020'.
} 
The dependent variable in this study is the assessment of the perception of professionals within the SMEs on the mandatory requirements set by the KCFR. Several questions were asked in the final section of the questionnaire to assess the dependent variable. The questions posed in the final section of the questionnaire included, were, e.g., the compliance to the KCFR standards besides preparing and reporting financial statements, the necessity for the possibility of reclassification of these requirements, do you have the adequate capacity within the firm to complete these requirements, is it a barrier for businesses these requirements according to the current classification, etc.

The study to achieve the set objectives has applied 5 (five) independent variables, the necessity of review for reclassification according to KCRF requirements, we prefer reclassification of requirements according to KCRF, expertise, and knowledge of accountants and auditors, continuing education in the context of ISA \& IFRS, and business owners assessment, were measured using a 'Likert Scale' points ranging from 1 (strongly disagree), 2 (disagree), 3 (neutral), 4 (agree), and 5 (strongly agree), indicating the lowest and highest agreement with the instruments tested. However, some items can be deleted if they fail the reliability and validity tests.

Table 2: Variable and Statistics Description (Source: Authors' calculation)

\begin{tabular}{|l|l|c|c|c|c|c|}
\hline \multicolumn{1}{|c|}{ Variables } & Description & Obs. & Mean & St.dv. & Min. & Max. \\
\hline Dependent Variable & & & & & \\
\hline $\mathbf{C}_{\text {KCFR }}$ & $\begin{array}{l}\text { Classification review by Kosovo Council for } \\
\text { Financial Reporting - KCFR }\end{array}$ & 229 & 1.21 & .057 & 1 & 3 \\
\hline Independent Variables & & & & & \\
\hline $\mathbf{N}_{\mathbf{K C F R}}$ & $\begin{array}{l}\text { Necessary reclassification review under } \\
\text { KCFR }\end{array}$ & 229 & 0.71 & .156 & 0 & 1 \\
\hline $\mathbf{P}_{\mathbf{K C F R}}$ & Preferred reclassification review under KCFR & 229 & 0.59 & .496 & 0 & 2 \\
\hline $\mathbf{E x p}_{\mathbf{k}}$ & $\begin{array}{l}\text { Experience knowledge of accountants and } \\
\text { auditors }\end{array}$ & 229 & 1.41 & .068 & 1 & 4 \\
\hline $\mathbf{E d u}_{\mathbf{c}}$ & Continuous education about KCFR \& IFRS & 229 & 1.13 & .371 & 1 & 3 \\
\hline $\mathbf{O w n}_{\boldsymbol{a}}$ & Assessments of business owners & 229 & 1.27 & .054 & 1 & 4 \\
\hline
\end{tabular}

Table 2 displays descriptive data for all factors employed in the analysis as requirements of IFRS for SME application. We find that statistically relevant variations occur among the test variables. From 229 observations made it turns out that the classification review by the Kosovo Council for Financial Reporting - KCFR has a mean value of 1.21 , with a standard deviation of 0.6 percent. Considering that the two parameters that are at the basis of the study, the reclassification requirement of microbusinesses has a mean value of 0.71 compared to the preferred reclassification requirements, which have a mean value of 0.59 . The initial result of this sample gives us 
indications that the common of micro-businesses have expressed a possible reclassification on compliance with IFRS for SMEs. The other evaluation parameter which is considered a promoter of the implementation of IFRS for SMEs is the experience and knowledge available to accountants and auditors, which has a mean value of 1.41 or expressed differently by 4 respondents 1.41 of them argued that knowledge is necessary for the implementation of these standards. Education as an important component of knowledge acquisition had approximately the same results as the previous parameter with a mean value of 1,13 was shown, with a standard deviation of 37,1 percent. And thus, the variable assessment of the business by owners has resulted in a mean value of 1,27 , with a standard deviation of $0,5 \%$, based on the measuring perception of business owners.

Table 3: Correlation Analysis (Source: Authors' calculation)

\begin{tabular}{|c|c|c|c|c|c|c|}
\hline & $\mathrm{C}_{\mathrm{KCFR}}$ & $\mathbf{N}_{\text {KCFR }}$ & $\mathbf{P}_{\text {KCFR }}$ & $\mathbf{D}_{\mathbf{P}}$ & $\mathbf{W}_{\mathbf{S}}$ & $\mathbf{L}_{S}$ \\
\hline $\mathrm{C}_{\mathrm{KCFR}}$ & 1.000 & & & & & \\
\hline $\mathbf{N}_{\text {KCFR }}$ & $-240 * *$ & 1.000 & & & & \\
\hline $\mathbf{P}_{\mathrm{KCFR}}$ & $.235^{\star *}$ & $-.597^{* *}$ & 1.000 & & & \\
\hline $\operatorname{Exp}_{k}$ & $.377^{\star \star *}$ & $.574^{\star \star}$ & $.191^{\star *}$ & 1.000 & & \\
\hline $\mathbf{E d u}_{\mathrm{c}}$ & $.109 *$ & $.312^{* *}$ & .160 & $-.159^{\star *}$ & 1.000 & \\
\hline $\mathrm{Own}_{a}$ & $.267^{*}$ & $.239 * \star$ & $.281^{\star}$ & -.098 & $.518^{\star \star}$ & 1.000 \\
\hline
\end{tabular}

Note: ${ }^{* *}$. Correlation is significant at the 0.01 level (2-tailed).

The output of the correlation matrix is presented in Table 3. The results show that the factors are unrelated, hence the problem of multi-collinearity among the independent factors is not present. The results show that the classification according to KCRF has a moderate association with the control parameters in the analysis. Significant positive association with 5 percent confidence level is reflected with preferred a possible classification by $\mathrm{KCRF}$, personnel expertise, while negative correlation exists with the requirement for possible reclassification by KCRF. There is also a positive association with the parameter of continuing education and evaluation by business owners at a level of reliability of 10 percent. While other associations among control parameters are presented in the table in detail.

Empirical Model

To develop an empirical model to assess the impact of micro-business requirements on the possibility of reconsidering the reclassification of mandatory requirements based on the set of documents defined by the KCFR, the empirical approach must be carefully chosen. Furthermore, we adapted ordinary probit regression to account for the binary nature of micro-business requests for financial reporting as well as the possibility of reclassifying this request. 
According to Cameron and Trivedi (2010), the evaluation takes into account the regressor's latent binary variable by changing the nature of the first-stage to a latent factors model similar to the probit. Assume $Y_{1}$ (Classification review by KCFR) is the dependent, and $\mathrm{Y}_{2}$ is the independent (Necessary reclassification review under KCFR and other control factors). We introduce an unobserved latent variable, $\mathrm{Y}_{2}^{*}$, which defines whether the $\mathrm{Y}_{2}=1$ or 0 . Formally, our model is represented as follows:

$$
\operatorname{Pr}(\mathrm{Y}=1 \mid \mathrm{X})=\varphi\left(\mathrm{X}^{\mathrm{T}} \beta\right)
$$

$\mathrm{P}_{\mathrm{r}}$ represents the possibility, as well as $\varphi$, reflects the standard distribution.

The likelihood approach is typically used to estimate $\beta$ constraints. In the situation of latent constructs, moreover, the technique is as follows:

$$
\begin{array}{r}
Y_{\mathrm{i}}^{*}=\mathrm{X}_{\mathrm{i}}^{\mathrm{T}}+\mu_{\mathrm{i}}=\beta_{0}+\beta_{1} \mathrm{X}_{\mathrm{i} 1}+\beta_{2} \mathrm{X}_{\mathrm{i} 2}+\cdots+\beta_{\mathrm{k}} \mathrm{X}_{\mathrm{ik}}+\varepsilon_{\mathrm{i}} \\
Y_{i}=\left\{\begin{array}{l}
1 \text { if } Y_{i}^{*} \geq \tau \\
0 \text { if } Y_{i}^{*} \leq \tau
\end{array}\right.
\end{array}
$$

Predicated on the formulas stated previously, the formula in our specific instance takes the form shown in equation number 4.

$$
\mathrm{Y}_{\mathrm{i}}^{*}=\mathrm{CR}_{\mathrm{i}}^{\mathrm{T}}+\mu_{\mathrm{i}}=\beta_{0}+\beta_{1} \mathrm{NC}_{\mathrm{i}, 1}+\beta_{2} \mathrm{PC}_{\mathrm{i}, 2}+\beta_{3} \mathrm{EK}_{\mathrm{i}, 3}+\beta_{4} \mathrm{CE}_{\mathrm{i}, 4}+\beta_{5} \mathrm{ABO}_{\mathrm{i}, 5}+\varepsilon_{\mathrm{i}}
$$

Where:

$\mathrm{Y}_{\mathrm{i}}^{*}-$ a countinous real

- valued index variable for observation $i$ that is unobserable, or a latent;

$\mathrm{X}_{\mathrm{i}}^{\mathrm{T}}-\left(1 \mathrm{X}_{\mathrm{i} 1} \mathrm{X}_{\mathrm{i} 2} \ldots \mathrm{X}_{\mathrm{ik}}\right), a 1 * k$ row vector of regressor values for observation $i$;

$\beta-\left(\beta_{0}, \beta_{1}, \beta_{2}, \ldots, \beta_{\mathrm{k}}\right) T$, a $K * 1$ column vector of regression coeficients;

$\mathrm{X}_{\mathrm{i}}^{\mathrm{T}} \beta-a 1 * 1$ scalar called the index function for observation $i$;

$\mu_{\mathrm{i}}$ - an id $N\left(0, \sigma^{2}\right)$ random error term for observation $i$.

\section{Econometric Findings}

The research in the section on econometric results covers specific concerns with a logical flow based on the definition of the econometric model, its adequacy, the potential difficulties, and parameter evaluation. The purpose of the ordered probit regression is to examine the influence on KCRF classification review of the specified parameters. Table 4 displays the results of -2 log-likelihood, as well as goodness-of-fit, Pearson \& Deviance on the stability of the model. Chi-square with coefficient 60,38 and probability $P=0.000$ is the essential approach for the model appropriateness which offers evidence of the model's fitness. In addition, regarding the stability of the model, the goodness-of-fit evaluation reveals that the Deviance coefficient is 44.13 with probability $\mathrm{P}=0.336$, which also provides proof that the model is properly selected (Petrucci 2009; Field 2018). 
Table 4: Model Fit and Goodness-of-Fit Information (Source: Authors' calculation)

\begin{tabular}{|l|c|c|c|c|c|c|c|c|}
\hline \multicolumn{5}{|c|}{ Model Fitting Information } & \multicolumn{3}{c|}{ Goodness-of-Fit } \\
\hline Model & $\begin{array}{c}-2 \text { Log } \\
\text { Likelihood }\end{array}$ & $\begin{array}{c}\text { Chi- } \\
\text { square }\end{array}$ & df & Sig. & & $\begin{array}{c}\text { Chi- } \\
\text { square }\end{array}$ & df & Sig. \\
\hline $\begin{array}{l}\text { Intercept } \\
\text { only }\end{array}$ & 130.445 & & & & Pearson & 61.935 & 29 & 0.093 \\
\hline Final & 70.061 & 60.384 & 9 & 0.000 & Deviance & 44.131 & 29 & 0.336 \\
\hline
\end{tabular}

Link function: Probit

The characteristic of the regression models on the suitability of the most useful is $R^{2}$, which in our study its role is played by Pseudo $R$ Square which in essence explains the dependence of the explanation of the variable depending on the applied control constraints. In our concrete case, Pseudo R Square has a coefficient of .571, which means that the control variables explain 57.1 percent of the classification review by KCRF. However, there are not many accurate explanations for the interpretation of this outcome from an observed point of view (Osborne 2015; Stevens and Pituch 2016), and this finding itself presents a restrained dosage. The study applied Durbin-Watson assessments in terms of serial correlation, the test results show a coefficient of 1.971 meaning that the test is located in the defined interval and proves that data are not autocorrelated (Durbin and Watson 1971; Racine and Hyndman 2002).

The valuation parameters besides the level of their importance are analyzed after the analytical tests described above. From Table 5, it can be seen that out of the five parameters applied in ordered probit regression, three of them have a substantial impact on the dependent variable 'necessities for a possible reclassification under KCRF mandatory requirements for micro-businesses, while the two other parameters have turned out to be not significant. 
Table 5: Parameter Estimates (Source: Authors' calculation)

\begin{tabular}{|c|c|c|c|}
\hline & & Estimate & Significance \\
\hline \multirow[t]{4}{*}{ Threshold } & Classification review by Kosovo Council for Financial Reporting $=1$ & -2.289 & .098 \\
\hline & Classification review by Kosovo Council for Financial Reporting $=2$ & -1.219 & .199 \\
\hline & Classification review by Kosovo Council for Financial Reporting $=3$ & -.651 & .360 \\
\hline & Classification review by Kosovo Council for Financial Reporting $=4$ & .568 & .195 \\
\hline \multirow[t]{5}{*}{ Location } & Necessary reclassification review under KCFR & 2.568 & .060 \\
\hline & Preferred reclassification review under KCFR & -.781 & .438 \\
\hline & Experience knowledge of accountants and auditors & 2.024 & .011 \\
\hline & Continuously education in relation to KCFR \& IFRS & 7.725 & .000 \\
\hline & Assessments of business owners & 5.314 & .996 \\
\hline \multicolumn{4}{|c|}{ Diagnostics } \\
\hline \multicolumn{2}{|c|}{ Likelihood ratio test } & 60.384 & 0.000 \\
\hline \multicolumn{2}{|c|}{ Pseudo R-square } & .571 & 0.003 \\
\hline \multicolumn{2}{|c|}{ Durbin-watson } & 1.971 & "-" \\
\hline \multicolumn{2}{|l|}{$N$} & 229 & "-" \\
\hline
\end{tabular}

Link function: Probit. Note. $\left(^{* * *}\right),\left(^{* *}\right),(*)$ significant respectively at 1,5 , and 10 percent.

The study used the significance of 1,5 , and 10 percent to test the parameter confirmation. The findings of the reclassification review parameter required under the KCRF have an important influence on the existing framework of KCRF compulsory requirements currently applicable in Kosovo. The evaluation parameter necessary reclassification review under the KCRF coefficient is 2,568, meaning that any increase per unit of this parameter will have a direct influence on the reclassification requirements of 2,6 units, presuming that the remaining parameters remain constant.

Those results, therefore, confirm the basic hypothesis that the requests of microenterprises are legitimate and important, and that is strong evidence of the policy framework beginning to examine the needs for such enterprises. The examination of macroeconomic determinants for adaptation to small and micro businesses for EU Member States (Bonito and Pais 2018) included a sample of 84 respondents who adapted and who failed to comply with these requirements in advanced and emerging countries. The findings of this study argue that these outputs might be due to costs transactions, the importance of having some knowledge of IFRS reporting assumed its difficulty, and belonging to IFRS-based countries that facilitate the adoption of IFRSs for SMEs. In addition, they concluded that this standard was less likely to be accepted by Eurozone Members. 
Based on these facts, then, the results of our study are fully consistent with Bonito and Pais (2018) arguments, and that micro-enterprises are necessary for a review of these criteria. Additionally, to compare the findings of the study have been confirmed by Perera and Chand (2015) by analyzing developed countries providing arguments that the package will have implications for the revision of IFRS for SMEs and will help in addressing future complications in the SME convergence process. Finally, in their study on the perception of the application of IFRS (Silva et al. 2021) argues that international accounting convergence de facto has not yet been reached in Portugal and Brazil, even after a period of seven to 8 years of adaption to those standards.

Moreover, the other two factors examined in this study include the experience of the accountants and the auditors, and the continuous education about IFRS for SMEs have shown significance for the implementation and adoption of those standards at 99,9 percent reliability. The study conducted by Sadikaj et al. (2020) reveals the substantial effect on adaption and application of such standard experience, a lack of guidance, and continuous education. The tests and verification of these hypotheses were done at a significant level of 95 percent were done via the ordered logit regression approach. In examining the advantages and drawbacks in the application of IFRS to SMEs (Ebaid 2021), it was discovered that the advantages are taken into consideration in terms of facilitating access to loans, facilitating credit rating, allowing for greater awareness, and interpretation. Whereas, in terms of difficulties, lack of adequate knowledge for IFRS and lack of training. It was concluded that the lack of appropriate resources and the lack of knowledge have a major influence on IFRS adoption for small and medium enterprises (Rodzani and Charles in 2016).

The results of our investigation are therefore fully consistent with the previous findings. The expertise of accountants and auditors has an important positive influence with a reliability of 1 percent on the dependent variable with the 2.024 coefficient, whereas ongoing training about IFRS for SMEs confirms the same positive level with a 7.725 coefficient. The parameters that have turned out to be insignificant are Preferred reclassification review under KCFR, and assessments of business owners as they have the value $P=0.438$, respectively $P=0.996$, and as such are insignificant in terms of their explanation.

\section{LIMITATIONS OF THE STUDY}

There are also limitations in the sample representation of this study, since our sample is only 229 , focusing mainly on micro-enterprises, on one hand, and this sample on the other represents the data gathered by relevant stakeholders, which in some instances could be produced in the insincerely supplied information. The outcomes of the research as such may thus not differ from the real situation but may be seen as a view of the stakeholders participating in the investigation. 
Moreover, when we deal with binary parameters, the empirical technique developed in this study is seen as more appropriate. The sole limitation of the probit models is that normal distributions are necessary for all unobserved utility components. In many, perhaps most situations, normal distributions provide an adequate representation of the random components. However, normal distributions are unsuitable in certain cases and might lead to perverse expectations.

\section{CONCLUSION}

Relying on empirical research by academics and researchers to date, who have analyzed specific countries, comparisons between the two countries, and panel countries on challenges and priorities during the so-called transitional phase of IFRS adaptation and implementation for SMEs.

For the countries of the Western Balkans and especially in the context of Kosovo, it is worth noting that there is a small amount of research. For this reason, this research can be considered as an advancement of the empirical literature in the Kosovo prospectus, and at the same time as an added value for researchers interested in this field. Thus, the research has applied qualitative and quantitative approaches, applying a sample stratified in 3 (three) subgroups, including 229 respondents who exercise their activity in SMEs and micro-businesses. To achieve the most stable results, ordered probit regression (OPR) has been applied, which is considered to be more appropriate when dealing with binary data (Petrucci 2009; Field 2018).

The main purpose of the research was to investigate the control parameters: micro-business necessities for a possible reclassification review of the criteria established by the KCRF; preferred requirements for a possible reclassification; experience of accountants and auditors; ongoing education for SMEs, and assessment by business owners. The econometric results argue that the requirements of SMEs, especially micro-businesses, the experience of accountants and auditors, as well as ongoing education on IFRS for SMEs have a significant impact on the standards applied and are considered as challenges for the development of these businesses. While the preference for a possible reclassification and evaluation according to business owners has turned out to be insignificant in adapting these requirements. One of the main drawbacks of these micro-businesses is that these requirements are an additional burden for their development, require the commitment of additional professional staff, and at the same time increase the financial cost. However, accountants and auditors also express their concern about the ongoing modifications of IFRS, which obliges them to have ongoing professional training to implement these IFRS for SMEs properly. Moreover, the situation created as a result of the Covid-19 pandemic has significantly influenced these categories to attend training and professional education in a physical way, which also presents an additional psychological burden. 
Thus, future research should attempt to explore other factors that could influence SMEs and microbusinesses' perception of the IFRS and to increase the sample size to cover a larger number of samples.

Policy Implication

Based on this finding and the conclusion of the study, the following suggestions may be drawn: policymakers should give equal and better emphasis to the requirements set by the KCRF for SMEs, and especially for micro-businesses provided that these micro-businesses have the opportunity to develop, sustainable growth, increase the number of employees, and then compulsorily adapt to IFRS requirements. KCRF should pay more attention to these micro-businesses by offering them more flexibility, as they are quite burdened with the requirements of the Tax Administration of Kosovo. Thus, policies that drive the growth of these micro-businesses and the economy of Kosovo as a whole need to be promoted which will have effects on GDP. One of the main concerns, to improve the quality of financial reporting as defined, is the adoption of policies that will allow favorable environments, including the legal and judicial system, the financial system, taxes, labor relations, investment procedures, and customs administration should be encouraged. 


\section{REFERENCES}

1. Ali Uyar and Ali Haydar Güngörmüşs. (2013). Perceptions and knowledge of accounting professionals on IFRS for SMEs: Evidence from Turkey, Research in Accounting Regulation, Volume 25, Number 1, pages 77-87, ISNN 1052-0457, https://doi.org/10.1016/j.racreg.2012.11.001.

2. Ana Bonito, Cláudio Pais. (2018). The macroeconomic determinants of the adoption of IFRS for SMEs, Revista de Contabilidad, Volume 21, Issue 2, Pages 116-127, ISSN 1138-4891, https://doi.org/10.1016/j.rcsar.2018.03.001.

3. Ana Paula Silva, Alexandra Fontes, and Adelaide Martins, (2021). Perceptions regarding the implementation of International Financial Reporting Standards in Portugal and Brazil. Journal of International Accounting, Auditing, and Taxation. volume (44), ISSN 1061-9518, https://doi.org/10.1016/j.intaccaudtax.2021.100416.

4. Anna-Maija Lantto. (2014). Business Involvement in Accounting: A Case Study of International Financial Reporting Standards Adoption and the Work of Accountants, European Accounting Review, 23:2, 335-356, https://doi.org/10.1080/09638180.2013.833411.

5. Ates, S. (2021). Accounting Convergence, Mandatory Adoption of IFRS, and Accounting Quality. In Y. Bayar (Eds.), Handbook of Research on Institutional, Economic, and Social Impacts of Globalization and Liberalization (pp. 605-627). IGI Global. https://doi.org/10.4018/978-1-7998-4459-4.ch033.

6. Callao, S., Jarne, J.I. and Laínez, J.A. (2007) Adoption of IFRS in Spain: Effect on the Comparability and Relevance of Financial Reporting. Journal of International Accounting, Auditing, and Taxation, 16, 148-178.

https://doi.org/10.1016/j.intaccaudtax.2007.06.002

7. Cameron, A. C., \& Trivedi, P. K. (2010). Microeconometrics using Stata. (Vol. 2). Stata press.

8. Chalmers, K., Clinch, G., \& Godfrey, J. M. (2011). Changes in value relevance of accounting information upon IFRS adoption: Evidence from Australia. Australian Journal of Management, 36(2), 151-173.

https://doi.org/10.1177/0312896211404571.

9. Clarkson, P., Hanna, J. D., Richardson, G. and Thompson, R. (2011): "The impact of IFRS adoption on the value relevance of book value and earnings", Journal of Contemporary Accounting \& Economics, Vol. 7, pp. 1-17.

10. Cormier, D., \& Magnan, M. L. (2016). The advent of IFRS in Canada: Incidence on value relevance. Journal of International Accounting Research, 15(3), 113-130.

11. Cormier, D., Demaria, S., Pascale, L.-A., \& Teller, R. (2009). First-time adoption of IFRS, managerial incentives and value-relevance: Some French evidence. Journal of International Accounting 
12. Daske, H. (2006). Economic benefits of adopting IFRS or US-GAAP - Have the expected cost of equity capital really decreased? Journal of Business Finance and Accounting, 33(3), 329-373. https://doi.org/10.1111/j.1468-5957.2006.00611.x.

13. De George, Emmanuel T., and Li, Xi, and Shivakumar, Lakshmanan. (2016). A Review of the IFRS Adoption Literature. Review of Accounting Studies, Forthcoming, http://dx.doi.org/10.2139/ssrn.2664475.

14. Dinuja Perera, Parmod Chand. (2015). Issues in the adoption of international financial reporting standards (IFRS) for small and medium-sized enterprises (SMEs), Advances in Accounting, Volume 31, Issue 1, Pages 165-178, ISSN 08826110, https://doi.org/10.1016/j.adiac.2015.03.012.

15. Enrico Dalla Riva and Bruno Meirelles Salotti. (2015). Adoption of the International Accounting Standard in Small and Medium-sized Enterprises and their Effects on Lending. Accounting \& Finance Magazine. 26 (69). https://doi.org/10.1590/1808-057×201512270.

16. Field, A. (2018). Discovering Statistics Using IBM SPSS Statistics. 5th Edition, SAGE Publications Ltd., London.

17. Florencia Roca. (2021) The influence of mandatory adoption of IFRS in Argentina on the value relevance of accounting information, Journal of Applied Economics, 24:1, 154-172, https://doi.org/10.1080/15140326.2021.1900695.

18. Ibrahim El-Sayed Ebaid. (2021). Benefits and challenges of implementing IFRS for SMEs: Descriptive evidence from Saudi Arabia. International Journal of Economics and Financial Issues,2021, 2 (1-2), PP: 31-50.

19. Durbin \& G.S. Watson. (1971), Testing for Serial Correlation in the least Squares Regression III. Biometrika 58, 1-19.

20. Jason W. Osborne. (2015). Best Practices in Logistic Regression. SAGE Publications Ltd., London. https://dx.doi.org/10.4135/9781483399041.

21. Kouki, A. (2018), "IFRS and value relevance: A comparison approach before and after IFRS conversion in the European countries", Journal of Applied Accounting Research, Vol. 19 No. 1, pp. 60-80. https://doi.org/10.1108/JAAR-05-2015-0041.

22. Leftwich, R. (2016). Accounting Information in Private Markets: Evidence from Private Lending Agreements.

23. Martha del Pilar Rodríguez García, Klender Aimer Cortez Alejandro, Alma Berenice Méndez Sáenz, Héctor Horacio Garza Sánchez, (2017). Does an IFRS adoption increase value relevance and earnings timeliness in Latin America?,Emerging Markets Review, Volume 30, 2017, Pages 155-168, ISSN 1566-0141, https://doi.org/10.1016/j.ememar.2016.11.001.

24. Neag, Ramona, Masca, Ema and Pascan, Irina, (2009), Actual aspects regarding the IFRS for SME - opinions, debates and future developments. Annales Universitatis Apulensis Series Oeconomica, 1, issue 11, https://EconPapers.repec.org/RePEc:alu:journl:v:1:y:2009:i:11:p:3. 
25. Petrucci, C. (2009). A Primer for Social Worker Researchers on How to Conduct a Multinomial Logistic Regression. Journal of Social Service Research, 35, 193 - 205.

26. Pituch, K. A., and Stevens, J. (2016). Applied multivariate statistics for the social sciences: Analyses with SAS and IBM's SPSS. (6th ed.), Taylor \& Francis, New York.

27. Poroy Arsoy, A. \& Sipahi, B. (2007). International Financial Reporting Standards for Small and Medium Enterprises and Turkey Example. Ankara University SBF Journal, 62 (04), 31-48. https://dergipark.org.tr/tr/pub/ausbf/issue/3082/42685>.

28. Research, 8(2), 1-22.

29. Roberts, C., \& Sian, S. (2006). Micro-Entity Financial Reporting: Perspectives of Preparers and Users.

30. Racine \& R. Hyndman. (2002), Using R To Teach Econometrics. Journal of Applied Econometrics 17, 175-189.

31. Sadikaj, B., Ahmeti, S., Aliu, M., \& Ismaili, H. (2020). Professional and practical challenges during the transition period from Kosovo Accounting Standards (KAS) to IFRS. Journal of Accounting, Finance, and Auditing Studies, 6(4), 64-78. https://www.um.edu.mt/library/oar/handle/123456789/61208.

32. Seán Byrne \& Bernard Pierce. (2007). Towards a More Comprehensive Understanding of the Roles of Management Accountants, European Accounting Review, 16:3, 469-498, https://doi.org/10.1080/09638180701507114.

33. Sikhwari Rudzani and Manda David Charles. (2016). An assessment of the challenges of adopting and implementing IFRSS for SMEs in South Africa. Problems and Perspectives in Management, 14 (2-1), 212-221. https://doi.org/10.21511/ppm.14(2-1).2016.10.

34. Ulf Brüggemann, Jörg-Markus Hitz \& Thorsten Sellhorn. (2013). Intended and Unintended Consequences of Mandatory IFRS Adoption: A Review of Extant Evidence and Suggestions for Future Research, European Accounting Review, 22:1, 1-37, https://doi.org/10.1080/09638180.2012.718487.

35. Y Sun and N Sari and S A H Havidz. (2021). The impact of IFRS adoption on value relevance accounting information: Evidence from Indonesia, Conference Series: Earth and Environmental Science. Volume 729, Number 1, https://doi.org/10.1088/1755-1315/729/1/012113.

36. Závodný, L. (2021). Relevance versus Reliability Trade-off in Financial Reporting among Companies Listed at Visegrad Group Stock Exchanges. European Financial and Accounting Journal, 16(1), 7-24. https://doi.org/10.18267/j.efaj.246.

37. Zeff, S. A. (1978) 'The rise of "economic consequences"', Journal of Accountancy, 146 (December), pp. 56-63. 